\section{ECCOMAS}

Proceedia
COMPDYN 2021

$8^{\text {th }}$ ECCOMAS Thematic Conference on Computational Methods in Structural Dynamics and Earthquake Engineering M. Papadrakakis, M. Fragiadakis (eds.) Streamed from Athens, Greece, 28 - 30 June 2021

\title{
FRAGILITY CURVES FOR RC FRAMED BUILDINGS CONSIDERING CUMULATIVE DAMAGE DUE TO EARTHQUAKE GROUND MOTION AND SLOW-MOVING LANDSLIDES
}

\author{
Fulvio Parisi ${ }^{1}$, Elia Acconcia $^{1}$ \\ ${ }^{1}$ Department of Structures for Engineering and Architecture, University of Naples Federico II \\ via Claudio 21, 80125 Naples, Italy \\ e-mail: fulvio.parisi@unina.it, elia.acconcia@unina.it
}

\begin{abstract}
Differential settlements during earthquake ground shaking at the base of framed buildings located on the crest of slopes can produce heavy damage. This reflects the importance of considering ground shaking and co-seismic vertical displacements as interacting hazards in seismic fragility assessment. Slow-moving landslides are indeed secondary hazards of earthquakes that can induce significant damage accumulation, increasing the seismic vulnerability of structures. This paper presents the main findings of a seismic fragility analysis that was carried out on $R C$ framed structures representative of low-rise, pre-code, residential Italian buildings. The methodology behind this study made use of fibre-based structural models and sequential nonlinear static analysis, which allowed the simulation of structural response to both earthquake ground motion and differential settlements with acceptable computational cost. Based on multivariate regression models available in the literature and random sampling of structures, seismically-induced settlements at the base of each structure were simulated considering multiple intensity measures (IMs) of seismic ground shaking. The correlation between the selected IMs was derived through a recent database of 250 accelerograms, which allow a wide representation of seismic hazard in the whole Italian territory for seismic risk assessment. The buildings were analysed with OpenSees software, assuming four performance limit states for characterization of seismic fragility at multiple levels of structural damage. The comparison between fragility curves associated with earthquake ground shaking only and those derived considering differential settlements allows the impact of cumulative damage to be evaluated.
\end{abstract}

Keywords: Seismic fragility, Reinforced concrete buildings, Fibre-based plasticity modelling, Earthquake-induced landslides, Cumulative damage.

ISSN:2623-3347 @ 2021 The Authors. Published by Eccomas Proceedia.

Peer-review under responsibility of the organizing committee of COMPDYN 2021.

doi: $10.7712 / 120121.8697 .18805$ 


\section{INTRODUCTION}

Post-earthquake reconnaissance missions have shown that earthquakes often produce slope instability, resulting in landslides that can exacerbate seismic damage to buildings and infrastructure and hence both life and economic losses. Buildings located on the crest of slopes can experience co-seismic displacements associated with slow-moving earthquake-induced landslides. This suggests considering the interaction between earthquake ground shaking and such landslides in seismic risk assessment of buildings. In this context, the development of probabilistic methodologies allows engineers, decision makers and stakeholders to carry out a multihazard risk analysis accounting for different sources of uncertainty in shaking and landslide hazards, vulnerability, and exposure.

In recent years, research developments in this field have been made, particularly in the case of reinforced concrete ( $\mathrm{RC}$ ) buildings but usually neglecting the uncertainties on their geometry and material properties that play a role in performance-based seismic assessment of existing structures. Foutopoulou and Pitilakis [1-3] studied the vulnerability of buildings to earthquakeinduced landslides, making use of three-dimensional finite element (FE) modeling and nonlinear time history analysis of both the slope and building. Nonetheless, that computational strategy can be too computationally demanding for seismic vulnerability assessment of building classes that are spatially distributed within a region.

In this study, a computationally efficient method for probabilistic vulnerability assessment of RC buildings subjected to earthquake-induced landslide hazard is presented. The proposed methodology builds upon a recent selection of strong ground motions oriented towards largescale risk assessment of buildings, which allows incorporating correlation between different intensity measures (IMs) used for earthquake ground shaking and slow-moving landslides.

\section{METHODOLOGY}

The vulnerability assessment described in this paper is based on a probabilistic procedure that allows modelling and propagation of uncertainties through fragility analysis, which is a well-established method in earthquake engineering [4]. After that a class of buildings with RC frame structure was selected, the correlation between two IMs used to describe the intensity of earthquake ground shaking and slow-moving landslide was investigated. In this respect, the selected IMs were the peak ground acceleration (PGA) and peak ground velocity (PGV), the correlation of which was investigated via 250 accelerograms that were recently selected in the ReLUIS-DPC 2019-2021 research project. The accelerograms were characterized by a wide amplitude range reflecting design spectra for L'Aquila, Italy (with return period ranging from 50 to 10,000 years), which was found to give a good representation of seismic hazard over the entire Italian territory [5]. Each accelerogram was characterized by a (PGA, PGV) pair, so the correlation between those IMs was studied over a set of 250 data points. More specifically, PGA and PGV were selected to measure the intensity of shaking and landslide, respectively.

After that seismic input was defined, the authors modelled the uncertainties in structural properties of the selected buildings, creating the basis for random generation of structural models. Random sampling was based on Monte Carlo simulation, which was fully implemented in MATLAB [6]. The structural capacity of RC buildings was defined through a fibre-based FE modelling approach using OpenSees software [7]. The seismic performance assessment of each random model of the RC structure was carried out by means of a sequence of nonlinear static analyses, in which the structural system was first subjected to incremental vertical differential settlement associated with the landslide, and subsequently to incremental horizontal displacement associated with earthquake ground shaking. Hence, the sequential nonlinear static analysis consisted of a nonlinear static analysis under incremental vertical settlement and a pushover 
analysis of the structure. The range of settlements impressed to the structure was based on the study by Foutopolou and Pitilakis [8], who proposed a predictive model that allows the prediction of peak co-seismic displacement based on the slope's characteristics and seismic input IMs. This allowed seismic displacement demand associated with slow-moving landslide to be predicted. Seismic displacement demand associated with ground shaking was evaluated according to the N2 method [9]. Seismic fragility of the selected buildings was evaluated with respect to four performance limit states corresponding to increasing damage levels. Each fragility point was derived under increasing PGA, allowing subsequent fitting of lognormal probability distribution to fragility data for development of fragility curves.

In the following sections, the methodology used in this study is described in detail.

\subsection{Selection of buildings}

The building class under study is that of low-rise residential buildings with RC frame structure built in Italy. The uncertainty modelling of those buildings involved consideration of both geometric and material properties. The case-study buildings had two storeys and rectangular plan, with frame systems consisting of 2 spans parallel to the slope crest and 3, 5, or 7 spans in the perpendicular direction. Beams were assumed to have the same span length in each longitudinal and transverse frame of the structure.

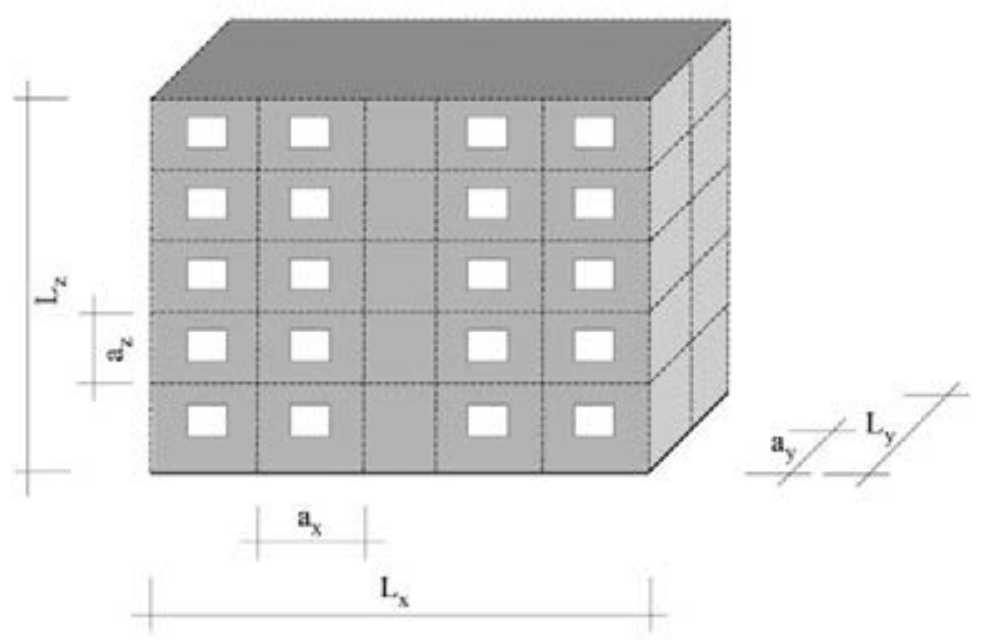

Figure 1: Case-study building with geometric random properties.

The mechanical properties of materials were identified by grouping the buildings by construction time according to the evolution of Italian codes. Both buildings built before 1971 (i.e., the year that marked the transition from design to gravity loads only to design for earthquake resistance) and those built between 1971 and 2008 in non-seismic areas according to past seismic zoning of Italy, were considered as pre-code. Low-code buildings were assumed to be those built in seismic areas between 1915 and 2008 according to old seismic design criteria (firstgeneration earthquake-resistant buildings). Medium-code and high-code buildings are those built after 2008, the former designed in low ductility class (second-generation earthquake-resistant buildings) and the latter in a high ductility class (third-generation earthquake-resistant buildings).

This study investigated the fragility of pre-code RC buildings built before 1971, assuming the following material properties: concrete with compressive strength having a mean value 
$f_{c m}=16.0 \mathrm{MPa}$ and coefficient of variation $\mathrm{CoV}=31 \%[10]$; and reinforcing steel with yield strength having a mean value $f_{y m}=369 \mathrm{MPa}$ and $\mathrm{CoV}=20 \%[11]$.

\subsection{Simulated design of structures}

The design of the structural elements was carried out using the design methods used at the time of construction $[12,13]$ and the Italian code in force in the same period [14] (Table 1).

\begin{tabular}{|c|c|c|}
\hline Item & Variable & Value \\
\hline \multirow{4}{*}{ Columns } & $b[\mathrm{~m}]$ & \multirow{2}{*}{ Derived by simulated design } \\
\hline & $h[\mathrm{~m}]$ & \\
\hline & $h_{i}[\mathrm{~m}]$ & 3.00 \\
\hline & $c[\mathrm{~mm}]$ & 30 \\
\hline \multirow{4}{*}{ Beams } & $b[\mathrm{~m}]$ & \multirow{2}{*}{ Derived by simulated design } \\
\hline & $h[\mathrm{~m}]$ & \\
\hline & $l[\mathrm{~m}]$ & {$[4,6]$} \\
\hline & $c[\mathrm{~mm}]$ & 30 \\
\hline
\end{tabular}

Table 1: Geometric properties.

The selected buildings were designed against gravity loads only according to the permissible stress method, which was based on the assumption of permissible stresses, linear elastic behaviour of materials, and effects superposition. Table 2 outlines the properties adopted for sizing of beams and columns.

\begin{tabular}{lll}
\hline Item & Property & Value \\
\hline \multirow{3}{*}{ Concrete } & $R_{c k}$ & $160 \mathrm{~kg} / \mathrm{cm}^{2}$ \\
& $\sigma_{c, \text { adm }, c}$ & $45 \mathrm{~kg} / \mathrm{cm}^{2}$ \\
& $\sigma_{c, \text { adm }, b}$ & $50 \mathrm{~kg} / \mathrm{cm}^{2}$ \\
\hline Steel & $\sigma_{f, \text { adm }}$ & $1400 \mathrm{~kg} / \mathrm{cm}^{2}$ \\
\hline & $A_{c, \text { min }}$ & $300 \times 300 \mathrm{~mm}^{2}$ \\
& $A_{f}$ & $0.8 \% \mathrm{~A}_{\min }$ \\
\hline \multirow{5}{*}{ Beams } & $B$ & $300 \mathrm{~mm}$ \\
& $H$ & $r \sqrt{M / b}$ \\
& $A_{f}$ & $t \sqrt{M b}$ \\
& $r$ & 0.446 \\
& $t$ & 0.00174 \\
& $A_{f, \text { min }}$ & $4 \varnothing 12$ \\
& Stirrups & $\varnothing 6 @$ min $\left(\mathrm{L}_{\min } / 2 ; 10 \emptyset_{\text {min }}\right)$ \\
\hline
\end{tabular}

Table 2: Parameters for simulated design of beams and columns.

\subsection{Definition of performance limit states}

The displacement approach used for vulnerability assessment suggests defining the performance limit states (LS) in relation to the strain capacity of the elements considered. According 
to the literature $[3,12]$, the strain thresholds listed in Table 3 were assumed in terms of maximum strains of steel $(\varepsilon s)$ and concrete $(\varepsilon c)$ as a function of the construction period. This definition of limit states is in line with the fibre-based FE modelling of the structure, which allows axial strain in materials to be monitored during structural analysis.

\begin{tabular}{ll}
\hline Limit State & Analytical definition \\
\hline LS1 & $\varepsilon_{c t, \max }=\varepsilon_{c t p}$ \\
LS2 & $\varepsilon_{s, \max }=0.0125 ; \varepsilon_{c c, \max }=0.0045$ \\
LS3 & $\varepsilon_{s, \max }=0.025 ; \varepsilon_{c c, \max }=0.006$ \\
LS4 & $\varepsilon_{s, \max }=0.045$ \\
\hline
\end{tabular}

Table 3: Definition of limit states.

LS1 was associated with slight damage and was assumed to be attained when the maximum tensile strain in concrete $\varepsilon_{c t \text {,max }}$ reached the cracking strain $\varepsilon_{c t p}$. LS2 was associated with moderate damage and was assumed to be attained when either the maximum tensile strain in steel $\varepsilon_{s, \text { max }}$ reached 0.0125 or the maximum compressive strain in concrete $\varepsilon_{c c \text {,max }}$ reached 0.0045 . Similar criteria were adopted for LS3 and LS4, which were respectively associated with severe damage and near collapse. In detail, LS3 was assumed to be attained when either $\varepsilon$ s,max reached 0.025 or $\varepsilon_{c c \text {, max }}$ reached 0.006 . The collapse limit state, i.e. LS4, was assumed to be attained when $\varepsilon_{s, \max }$ reached 0.045 .

\section{DISPLACEMENT DEMAND DUE TO EARTHQUAKE-INDUCED LANDSLIDE}

As briefly discussed in Sect. 2, 250 accelerograms compatible with design spectra for L'Aquila, Italy (with return period ranging from 50 to 10,000 years), were selected to cover a very wide range of shaking intensities and to allow risk assessment at any site of Italy. Figure 3 shows a bi-logarithmic scatter plot of PGA and PGV for selected ground motions.

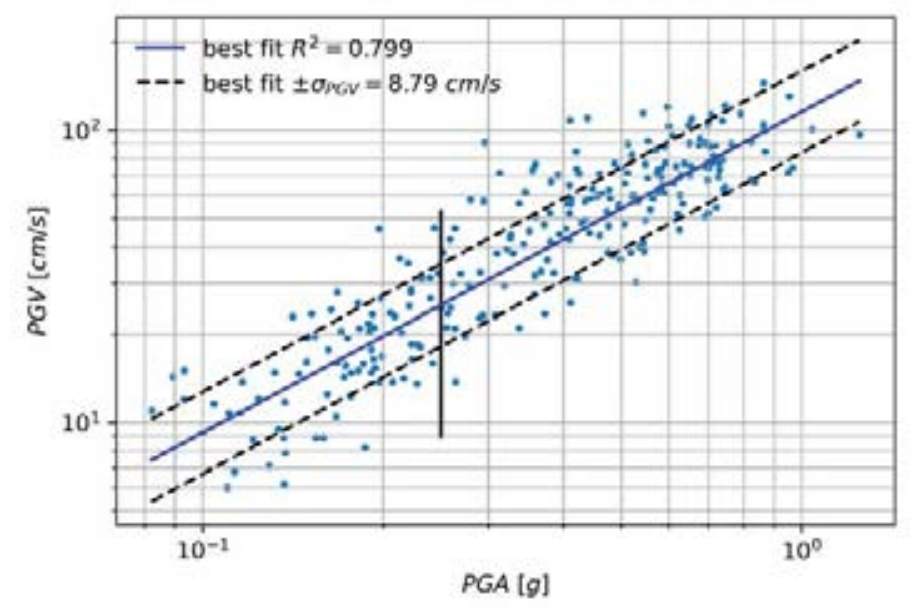

Figure 2: Correlation between PGV and PGA of selected accelerograms.

A regression analysis was performed using the power function as model, which on the bi-logarithmic plane is represented by a straight line. Based on the $(P G A, P G V)$ pairs of the selected accelerograms, the following equation was obtained:

$$
P G V=121.3 P G A^{1.097}
$$


with a coefficient of determination $R^{2}=0.799$ and standard deviation $\sigma_{P G V}=8.79 \mathrm{~cm} / \mathrm{s}$. Such a regression model allows the random generation of PGV conditioned upon PGA as expected conditional value of PGA plus a sample of the model error, the latter being assumed as lognormal random variable with zero mean and standard deviation equal to $\sigma_{P G V}$. Figure 4 shows the distribution of $\mathrm{PGV}$ given $P G A=0.25 g$.

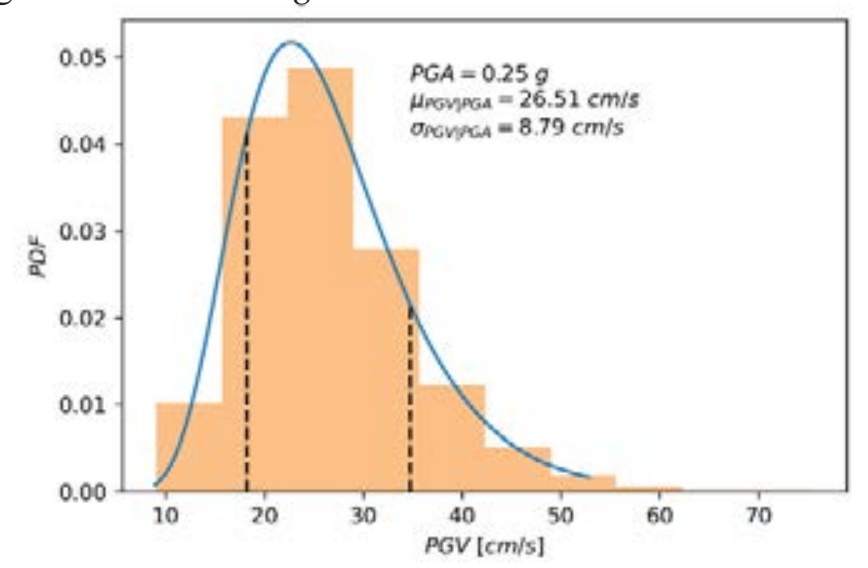

Figure 3: Probability distribution of conditional PGV given $\mathrm{PGA}=0.25 g$.

In order to evaluate the permanent displacement $D$ induced by the earthquake, the study conducted by Fotopoulou and Pitilakis [5] was taken into account. Those researchers developed 5 different predictive models based on single or multiple IMs. In this study, the following predictive model was used:

$$
\ln (D)=-8.360+1.873 \ln (P G V)-0.347 \ln \left(k_{y} / P G A\right)-5.964 k_{y} \pm 0.64 \epsilon
$$

which allows the prediction of $D$ given $P G A, P G V$ and $k_{y}$, assuming $k_{y}$ as yield acceleration coefficient of the slope, $\varepsilon$ is the standard normally distributed variable with zero mean and unit standard deviation and 0.64 is the logarithmic standard deviation.

To take into account the different configurations of the slope, reference was made to the yield acceleration coefficient $k_{y}$ that summarizes the effects of both geometric and mechanical characteristics of the slope, the relative location of the building with respect to the slope, and the effects of gravity loads transmitted from the building to the slope.

To cover the majority of cases, 5 values of the parameter $k_{y}$ were considered, namely, $0.05 g$, $0.10 g, 0.15 g, 0.20 g$, and $0.25 g$. For each $k_{y}$-value, 10 levels of PGA between 0 and $1.0 \mathrm{~g}$ were considered, resulting in 50 combinations. For each value of $k_{y}$ and $P G A, 10^{3}$ samples of the building class were randomly generated through Monte Carlo method in order to obtain a sample that is representative of the existing buildings.

\section{SEQUENTIAL STRUCTURAL ANALYSIS}

The analysis was conducted using the OpenSees opensource software [7]. OpenSees allows users to simulate the response of structural and geotechnical systems subjected to seismic input and/or other types of actions. The construction of a finite element model and subsequent analysis must be implemented in OpenSees through a code in TCL or with more recent versions in Python. For this reason, OpenSees is well suited for applications in the research field, especially when using parametric models for the evaluation of building classes.

Once the geometric, mechanical and load models were defined, the analysis procedure consisted in the application of gravity loads through a first analysis step with force control. 
Afterwards, a modal analysis was carried out to identify the first-mode shape to define the corresponding profile of horizontal seismic actions.

The second analysis stage consisted in the application of the settlement at the base of the columns subjected to the landslide. That analysis was carried out with displacement control, assuming a gradually increasing displacement with step equal to $1 \mathrm{~mm}$. In each analysis step, the reaction force at the base of the columns affected by the settlement was computed to check whether columns were compressed. Otherwise, the support at the base nodes was removed in the subsequent analysis phases.

At this point, a nonlinear incremental static (pushover) analysis was performed with displacement control to assess the structural performance under horizontal seismic actions. The roof centroid was assumed as a control point and the first-mode shape of the structure was used to generate the lateral load profile proportional to the product of modal displacements by inertia masses. Pushover analysis was carried out by increasing the roof displacement by $10 \mathrm{~mm}$ until a peak base shear degradation of $75 \%$ was attained.

Structural performance was assessed during each analysis stage, checking whether axial strains in frame members reached their limit states thresholds outlined in Table 3. In that way, the capacity in terms of displacement associated with each limit state was evaluated.

Whilst seismic demand in terms of vertical displacement was predicted through the model into Eq. (2), the seismic demand associated with horizontal ground shaking was estimated according to the N2 method [9]. Accordingly, the base shear versus roof displacement curve derived through pushover analysis was transformed into the corresponding capacity curve of an equivalent single-degree-of-freedom (SDOF) system, allowing the seismic demand assessment by means of inelastic displacement spectra. The displacement demand was computed for each considered PGA level and compared to the capacity associated with each limit state, allowing the authors to assess whether each limit state was exceeded.

\section{DEVELOPMENT OF FRAGILITY CURVES}

Given a prescribed value of $k_{y}$, for each $P G A$ level the conditional probability of exceeding a prescribed limit state was estimated as the ratio of the number of failure cases $N_{f}$ to the total number of simulations (i.e., $N_{\text {sim }}=10^{3}$ ). This allowed the computation of counted fragility under varying $P G A$. A lognormal probability distribution was then fitted to fragility points to develop a fragility curve for each limit state. Figure 6 shows the fragility curves corresponding to $k_{y}=0.15 \mathrm{~g}$ for all limit states, considering either ground shaking only (dashed lines identified as EQ in the figure legend) or both the combined effect of seismic ground shaking and co-seismic settlement due to slow-moving landslide (solid lines identified as EQ + L in the figure legend). Table 4 outlines the median value of $P G A$, denoted by $P G A 50$, and dispersion $\beta$ corresponding to each limit state.

\begin{tabular}{ccccc}
\hline \multirow{2}{*}{ LS } & \multicolumn{2}{c}{ Ground shaking } & \multicolumn{2}{c}{ Ground shaking + landslide } \\
\cline { 2 - 5 } & $P G A_{50}[g]$ & $\beta$ & $P G A_{50}[g]$ & $\beta$ \\
\hline LS1 & 0.0055 & 0.7535 & 0.0055 & 0.7535 \\
\hline LS2 & 0.1312 & 0.4327 & 0.1054 & 0.4125 \\
\hline LS3 & 0.1752 & 0.4292 & 0.1403 & 0.4120 \\
\hline LS4 & 0.7233 & 0.4051 & 0.3034 & 0.4204 \\
\hline
\end{tabular}

Table 4: Median and dispersion of fragility curves. 


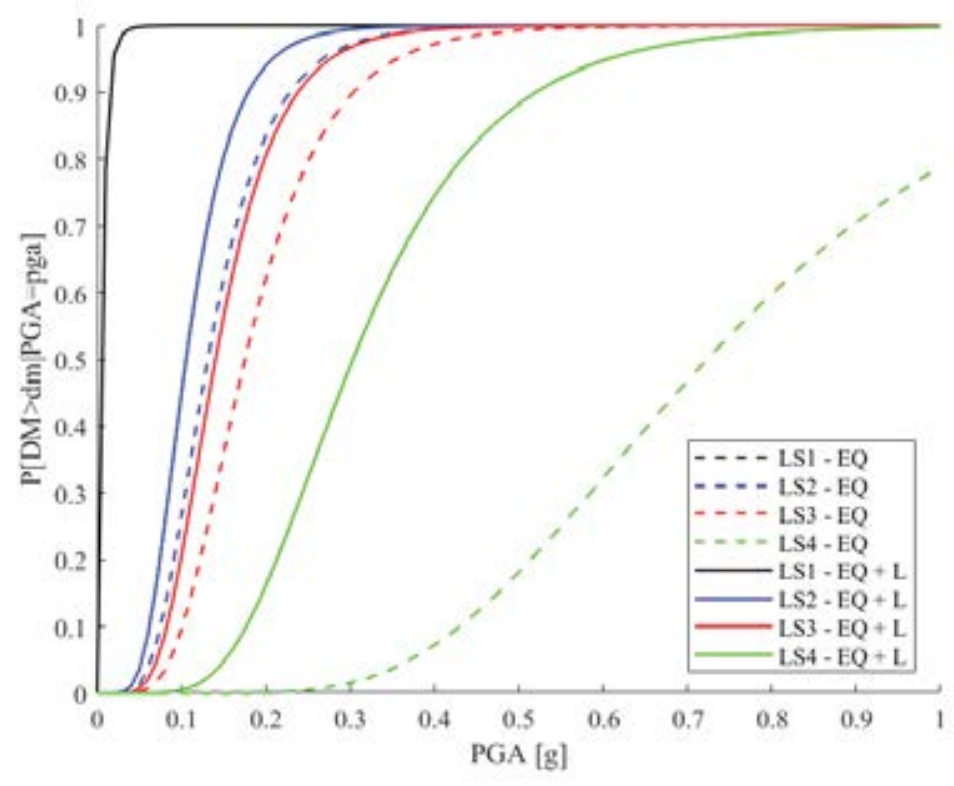

Figure 4: Fragility curves.

The fragility curves show a high vulnerability of the case-study building class even without considering the effect of co-seismic settlement. As expected, slight damage (LS1) consisting of concrete cracking takes place at very low levels of $P G A$. For the limit state of collapse (LS4), the co-seismic settlement has a major impact on seismic vulnerability, reducing $P G A_{50}$ from $0.72 \mathrm{~g}$ to $0.30 \mathrm{~g}$. A lower increase in median $P G A$ with decreasing dispersion is found for the limit states of moderate damage (LS2) and severe damage (LS3).

The horizontal distance between median values of the fragility curves is a measure of the ductility available in the structure of the case-study buildings. In this respect, the relatively small distance between the fragility curves corresponding to LS2 and LS3 indicates a rather limited ductility of pre-code RC buildings.

\section{CONCLUSIONS}

In the present study, the seismic vulnerability of existing $\mathrm{RC}$ buildings subjected to earthquake-induced landslides has been assessed. Buildings placed upstream of the slope and therefore exposed to the effects of co-seismic settlements were considered. Lumping the geometric and geotechnical characteristics of the slopes as well as the presence and relative distance of buildings through the yield acceleration coefficient, 1000 building samples were randomly generated, based on Monte Carlo method. For each sample, a simulated design was carried out to determine the dimensions of the member cross-sections and their reinforcement. Each building model was modelled and analysed in OpenSees by first imposing co-seismic vertical displacements associated with slow-moving landslide and then horizontal displacements associated with seismic ground shaking. Seismic performance under both earthquake-induced landslide and horizontal ground shaking was evaluated through nonlinear static analysis with displacement control. For each sample, the displacement capacity corresponding to four limit states was evaluated and compared to demand, allowing fragility estimation under varying PGA. The lognormal distribution was fitted to fragility points to develop fragility curves.

The proposed methodology makes it possible to assess the vulnerability of RC frame buildings to seismically-induced landslides through a fully mechanics-based approach. This allows drawbacks of empirical vulnerability assessment methods to be overcome, particularly when observed damage data on buildings struck by earthquake-induced landslides are lacking. It is 
also emphasised that the proposed methodology based on fibre-based FE modelling and sequential nonlinear static analysis has a very low computational cost with respect to nonlinear time history, allowing a very large number of simulations on 3D building structures. For each case study (i.e., yield acceleration coefficient), 10,000 analyses on 1000 structural models subjected to 10 levels of seismic intensity were carried out on a personal computer equipped with 8 cores, a $3.6 \mathrm{GHz}$ processor and $32 \mathrm{~GB}$ RAM. This allowed 1 analysis per minute, leading to a total duration of 7 days for the entire fragility analysis to be completed.

\section{ACKNOWLEDGMENTS}

This study was developed in the framework of POR GRISIS project (Gestione dei rischi e sicurezza delle infrastrutture a scala regionale), which was funded by Campania Region through POR FESR 2014-2020 programme.

\section{REFERENCES}

[1] S.D. Fotopoulou, K.D. Pitilakis, Fragility curves for reinforced concrete buildings to seismically triggered slow-moving slides. Soil Dynamics and Earthquake Engineering, 48, 143-161, 2013.

[2] S.D. Fotopoulou, K.D. Pitilakis, Probabilistic assessment of the vulnerability of reinforced concrete buildings subjected to earthquake induced landslides, Bulletin of Earthquake Engineering, 15, 5191-5215, 2017.

[3] S.D. Fotopoulou, K.D. Pitilakis, Vulnerability assessment of reinforced concrete buildings at precarious slopes subjected to combined ground shaking and earthquake induced landslide. Soil Dynamics and Earthquake Engineering, 93, 84-98, 2017.

[4] K.A. Porter, R.P. Kennedy, R.E. Bachman, Creating fragility functions for performancebased earthquake engineering. Earthquake Spectra. 23 (2), 471-489, 2007.

[5] V. Manfredi, A. Masi, R. Paolucci, A.G. Ozcebe, C. Smerzini, Selection and frequencyscaling of seismic input for deriving analytical fragility curves of RC existing buildings, Bulletin of Earthquake Engineering (to be submitted).

[6] MATLAB (R2019b). Natick, Massachusetts: The MathWorks Inc., 2018.

[7] F. McKenna, OpenSees: A framework for earthquake engineering simulation. Computing in Science \& Engineering, 13(4), 58-66, 2011.

[8] S.D. Fotopoulou, K.D. Pitilakis, Predictive relationships for seismically induced slope displacements using numerical analysis results. Bulletin of Earthquake Engineering, 13, 3207-3238, 2015.

[9] P. Fajfar, Capacity spectrum method based on inelastic demand spectra, Earthquake Engineering and Structural Dynamics, 28, 979-993, 1999.

[10] A. Masi, M. Vona, Vulnerability assessment of gravity-load designed RC buildings: Evaluation of seismic capacity through non-linear dynamic analyses. Engineering Structures, 45, 257-269, 2012. 
[11] G.M. Verderame, A. Stella, E. Cosenza, Le proprietà meccaniche degli acciai impiegati nelle strutture in ca realizzate negli anni '60. Proceedings of X Congresso Nazionale "L'Ingegneria Sismica in Italia”, Potenza-Matera, 2001.

[12] H. Crowley, R. Pinho, J. J. Bommer, A Probabilistic Displacement-based Vulnerability Assessment Procedure for Earthquake Loss Estimation. Bulletin of Earthquake Engineering, 2, 173-219, 2004.

[13] L. Santarella, Il cemento armato - La tecnica e la statica, vol. I, Hoepli, 1956.

[14] Regio Decreto del 16/11/1939 n. 2229, Norme per la esecuzione delle opere in conglomerato cementizio semplice ed armato, Rome. 